pital lobe was removed and the histology of this showed that it was a moderately differentiated adenocarcinoma, possibly related to his previous carcinoma of the ampulla of Vater. He made an uneventful recovery. During the next few days he made remarkable improvement except for his persistent left homonymous hemianopia, and he was allowed home on 28 February. Since then he has been followed by one of our colleagues in the outpatient department, and he is remarkably well and symptom-free.

Thus we feel surgery has a place in the management of metastatic cerebral lesions in spite of its grim prognosis. This is apparent from this case.

We thank Dr. J. A. Tulloch for permission to publish this case.

-We are, etc.,

Medical Unit,

Stracathro Hospital,

C. DE VoIL.

S. N. SINHA.

\section{Fluphenazine Enanthate in the Maintenance Treatment of Schizophrenia}

SIR,-Since the publication of Dr. N. S. Capstick's report from Graylingwell (20 January, p. 181) I have reviewed the patients treated with fluphenazine enanthate at St. Cadoc's Hospital since the introduction of the drug in February 1966. A total of 150 patients have been treated, and 100 of these have had the drug for longer than six months. A breakdown of length of treatment in these 100 patients is as follows:

\begin{tabular}{|c|c|c|c|}
\hline \multicolumn{3}{|c|}{ Length of Treatment } & No. of Patients \\
\hline 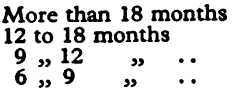 & 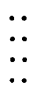 & $\begin{array}{l}\because \\
\because \\
\because\end{array}$ & $\begin{array}{l}21 \\
27 \\
33 \\
19\end{array}$ \\
\hline
\end{tabular}

This group is unselected, and apart from seven patients diagnosed as acute schizophrenia with relapse in the first year of illness and one patient unsatisfactorily diagnosed as pseudo-psychosis, all are chronic schizophrenics. No patient had oral fluphenazine prior to the enanthate, and the dosage of the latter varied from $0.5 \mathrm{ml}$. monthly to $1 \mathrm{ml}$. weekly, although all commenced therapy with $1 \mathrm{ml}$. fortnightly. Anti-Parkinsonian drugs have been used routinely throughout the treatment.

Like that at Graylingwell the St. Cadoc's study has been to assess side-effects associated with long-term treatment with fluphenazine enanthate, although naturally clinical assessment of the patients' state has also been made. This has revealed the following: complete control of symptoms, 62 ; improved but not asymptomatic, 17 ; no change, 21.

In 14 patients discharged for a year or more, time spent in hospital during the five years before their treatment with fluphenazine enanthate totalled 176 months. In the year following discharge they have spent a total of only five months in hospital, accounted for by the readmission of three patients, two of them for social reasons and one for relapse after his family doctor had stopped his fluphenazine enanthate. All have since been redischarged. Generally, sideeffects have not proved too troublesome, and

in only four instances was the drug withdrawn on this account. I have, however, recorded the onset of side-effects after months of treatment, and the following Table is taken from a paper already prepared for publication.

\begin{tabular}{|c|c|c|}
\hline $\begin{array}{l}\text { Type of } \\
\text { Side-effect }\end{array}$ & $\begin{array}{l}\text { Variation in Time } \\
\text { of Onset }\end{array}$ & Average \\
\hline 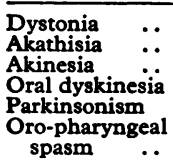 & $\begin{array}{l}3 \text { days to } 8 \text { months } \\
1 \text { week to } 8 \\
5 \text { months to } 6 \text { months } \\
2 \text { d" } 13 \text { " } \\
10 \text { days to } 13 \text { " } \\
2 \text { weeks ( } 1 \text { case only) }\end{array}$ & 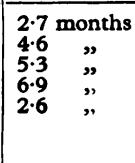 \\
\hline
\end{tabular}

This would appear to be at variance with the experience of other psychiatrists who have used the drug.

A further point I should like to discuss is the statement made by Dr. Capstick when disposing of the argument that depot phenothiazines are of little gain when oral antiParkinsonian drugs are required concomitantly. He states, "This is not a valid argument in so far as there is an incentive to take anti-Parkinsonian drugs as a relief from side-effects. ..." I have previously written similarly, ${ }^{2}$ but now realize that this applies entirely only to my patients who had dystonic reactions (6) and akinesia (3). In this series $50 \%$ of patients with akathisia or Parkinsonism, and none of the few patients with oral dyskinesia or oropharyngeal spasm, were aware of their symptoms. The neces sity for regular follow-up, therefore, is obvious, more so as these reactions are all potentially reversible.

The overall incidence of side-effects in this series was $41 \%$. Complete control was obtained in $61 \%$ of all side-effects by varying the dosage of fluphenazine enanthate and anti-Parkinsonian drugs. As previously stated, in only four patients having a total of eight side-effects $(17 \%)$ between them was considered necessary to stop the drug. The remaining side-effects were controlled to a sufficient degree to warrant continuing it These figures compare favourably with those quoted by $\mathrm{Ayd}^{3}$ for oral phenothiazines. $\mathrm{He}$ found $60 \%$ of patients treated with trifluoperazine; $52 \%$ of those treated with fluphenazine and $43 \%$ treated with prochlorperazine developed extrapyramidal reactions.

I agree wholeheartedly with Dr. Capstick's view that intramuscular fluphenazine is a safe treatment and I consider it to be the treatment of choice in schizophrenic patients with a chronic relapsing illness.-I am, etc.

St. Cadoc's Hospital,
Caerleon.

JOHN LOWTHER.

\title{
REFERENCES
}

1 Millar, J., Brit. med. f., 1966, 2, 1262. 2 Lowther, J., Brit. F. Psychiat,, 1967, 113, 557. 